\section{Military Technical College Kobry El-Kobbah, Cairo, Egypt}

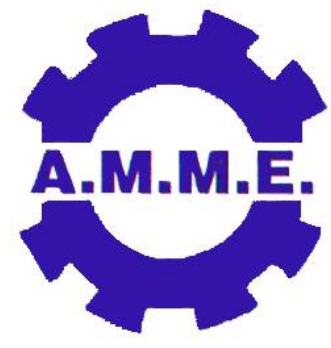

14th International Conference on

Applied Mechanics and

Mechanical Engineering.

\title{
Dynamic Analysis of A Modified Truck Chassis
}

By

\author{
R.Hoseini * \\ M.R.Forouzan **
}

\begin{abstract}
:
The paper investigates the vibration characteristics of the truck chassis including the natural frequencies and mode shapes. When the truck travels along the road, the truck chassis is excited by dynamic forces caused by the road roughness, engine, transmission and more. Modal analysis using Finite Element Method(FEM) can be used to determine natural frequencies and mode shapes. In this study, the modal analysis has been accomplished by the commercial finite element packaged ANSYS. The model has been simulated with appropriate accuracy and with considering the effect of bolted and riveted joints. The chassis has been altered by some companies for use in municipal service(street sweepers) and it raises the question: Are natural frequencies of the modified chassis in suitable range? After constructing finite element model of chassis and appropriate meshing with shell elements, model has been analysed and first 30 frequencies has been expanded. In addition, the relationship between natural frequencies and engine operating speed has been explained. Finally advantages of the modified chassis which leads to the increase of the natural frequencies and placing them in the appropriate range has been discussed.
\end{abstract}

\section{Keywords:}

vibration, Truck chassis, Dynamic, Modal Analysis ,Shell elements

* Student of engineering, Department of Mechanical Engineering, Sharif University of Technology 
** Assistant professor, Department of Mechanical Engineering, Isfahan University of Technology

\section{Introduction:}

The dynamic response of simple structures, such as uniform beams, plates and cylindrical shells, may be obtained by solving their equations of motion. However, in many practical situations either the geometrical or material properties vary, or the shape of the boundaries cannot be described in terms of known mathematical functions. Also, practical structures consist of an assemblage of components of different types, namely beams, plates, shells and solids. In these situations it is impossible to obtain analytical solutions to the equations of motion [1]. This difficulty is overcome by seeking some form of numerical solutions and finite element methods.

Automotive industry is one of the biggest users of the technology of modal analysis. The modal behavior of car chassis is a part of most necessary information for the inspection into car's dynamic behavior. In this essay the modal analysis of truck chassis has been studied.

As a truck travels along the road, the truck chassis is excited by dynamic forces induced by the road roughness, engine, transmission and more. Under such various dynamic excitations, the truck chassis tends to vibrate [2]. Whenever the natural frequency of vibration of a machine or structure coincides with the frequency of the external excitation, there occurs a phenomenon known as resonance, which leads to excessive deflections and failure. The literature is full of accounts of system failures brought about by resonance and excessive vibration of components and systems [3].

The global vibrational characteristic a vehicle are related to both its stiffness and mass distribution. The frequencies of the global bending and torsional vibration modes are commonly used as benchmarks for vehiclestructural performance. Bending and torsion stiffness influence the vibrational behavior of the structure, particularly its first natural frequency[4].

The mode shapes of the truck chassis at certain natural frequencies are very important to determine the mounting point of the components like engine, suspension, transmission and more. Therefore it is important to include the dynamic effect in designing the chassis[2].

Many researchers carried out study on truck chassis. Vasek and his cooperators (1998), have analysed a truck dynamically. In their method in addition to simulating truck with finite element packaged ANSYS and being sure that structure vibrational modes are in appropriate range, they vibrationally analysed it[ 5]. Yuan Zhang and Arthur Tang (1998), compare natural frequencies of a ladder chassis with finite element and experimental methods[6]. Guo and chen (2008), research into dynamic and modal analysis of a space chassis (complex 3-dimensional chassis) and analyse transient response using the principal of superposition [7].

This paper deals with a 6 ton truck chassis that includes natural frequencies and mode shapes. This chassis has been shortened by related companies for use in municipal service (street sweeper) and here we face the challenge and it raises the question: Are natural frequencies of the modified chassis in suitable range? 
In the studied model unlike the most previous models, rivets and bolts have been modeled completely. Also shell element has been used for analysis. This element has better and more disciplined meshing in comparison with other elements and has the capability of gaining more accurate results with the same meshing containing the related 3-dimensional elements. It is mentionable that validity of the results have been verified by comparing the results from a similar model with the model proposed by Mr Foui and his cooperator[2].

\section{Truck chassis:}

In this paper, a 6 ton truck chassis has been studied. This truck chassis is a ladder chassis and its longitudinal and cross connecting sections are channel shaped. Automotive view with dimensional plan and dimensions have been illustrated in Figure (2) and table (1). Chassis material is JIS-SAPH41 with $7800 \mathrm{~kg} / \mathrm{m} 3$ density and $520 \mathrm{MPa}$ yield strength and $590 \mathrm{MPa}$ tensile strength:
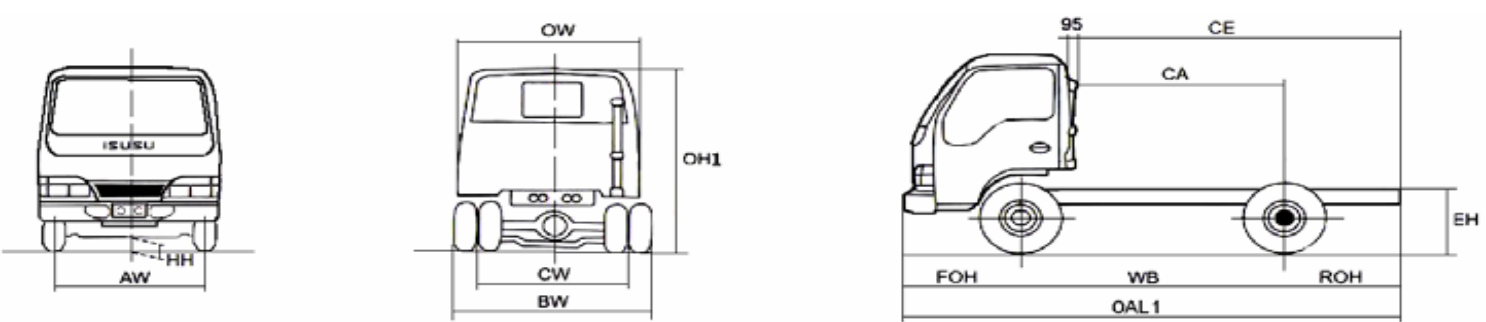

Figure (1) Dimensional plane of truck

Table (1) Truck dimensions related to figure(1)

\begin{tabular}{|l|l|l|l|l|l|l|l|l|l|l|l|l|}
\hline EH & HH & OH1 & CW & BW & AW & OW & CA & CE & ROH & FOH & WB & OAL1 \\
\hline 830 & 210 & 2220 & 1650 & 2115 & 1680 & 1995 & 3195 & 4910 & 1700 & 1085 & 3815 & 6600 \\
\hline
\end{tabular}

\section{Finite-element model}

Truck chassis has been modeled with 4-node shell element in ANSYS. Numerical studies on simple hollow rectangular beam show that this element is suitable for creating and meshing the model and it yields accurate results. The element used has 4 nodes with 6 degrees of freedom and is appropriate for linear and nonlinear deformations and also large deflections. There are approximately 70000 elements in the model that has proved suitable in comparison with other cases, so that the error in each case is less than one percent. 

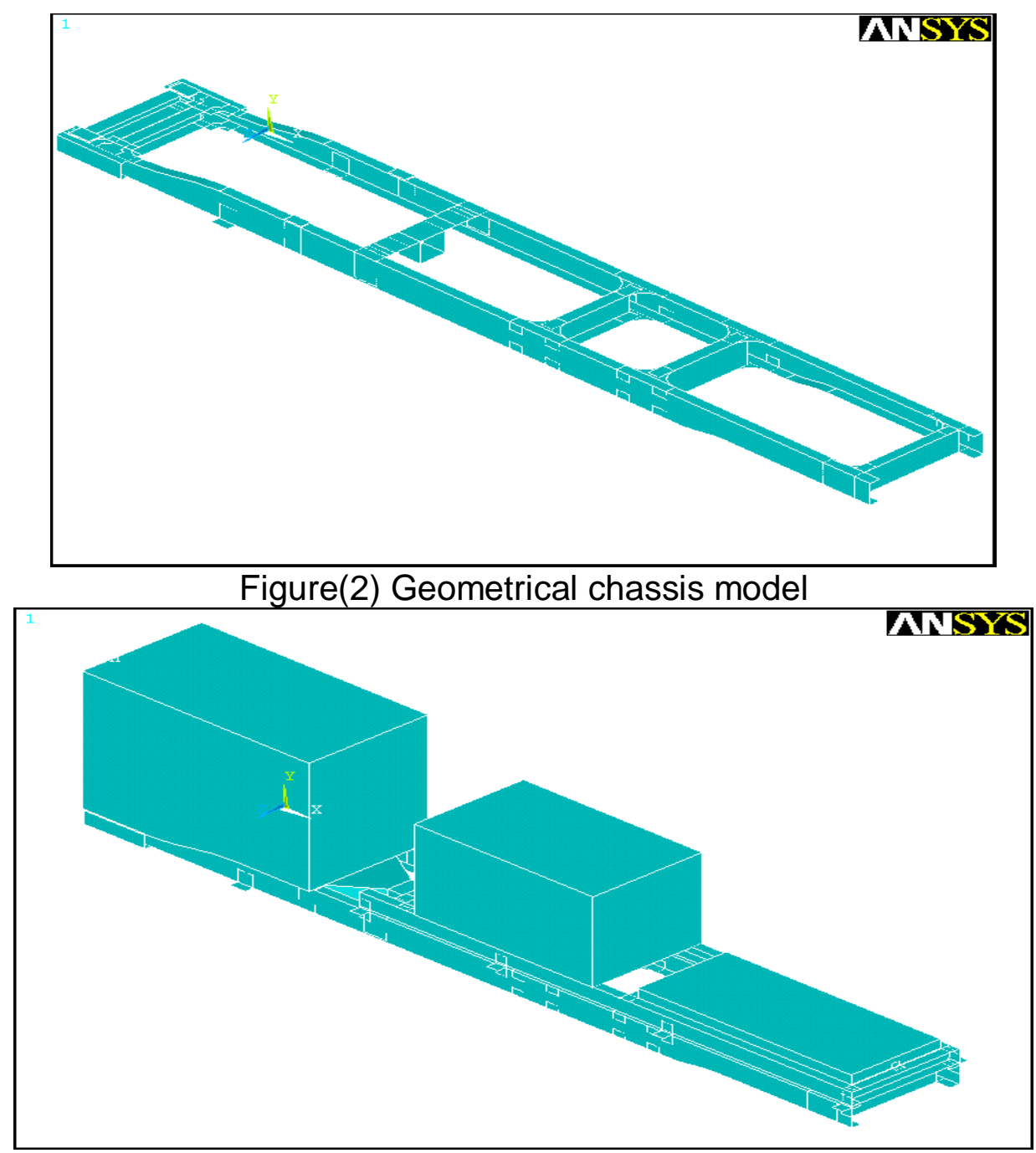

Figure(3) Geometrical truck model

Model with appropriate accuracy and with considering bolts and riveted joints effects has been simulated.
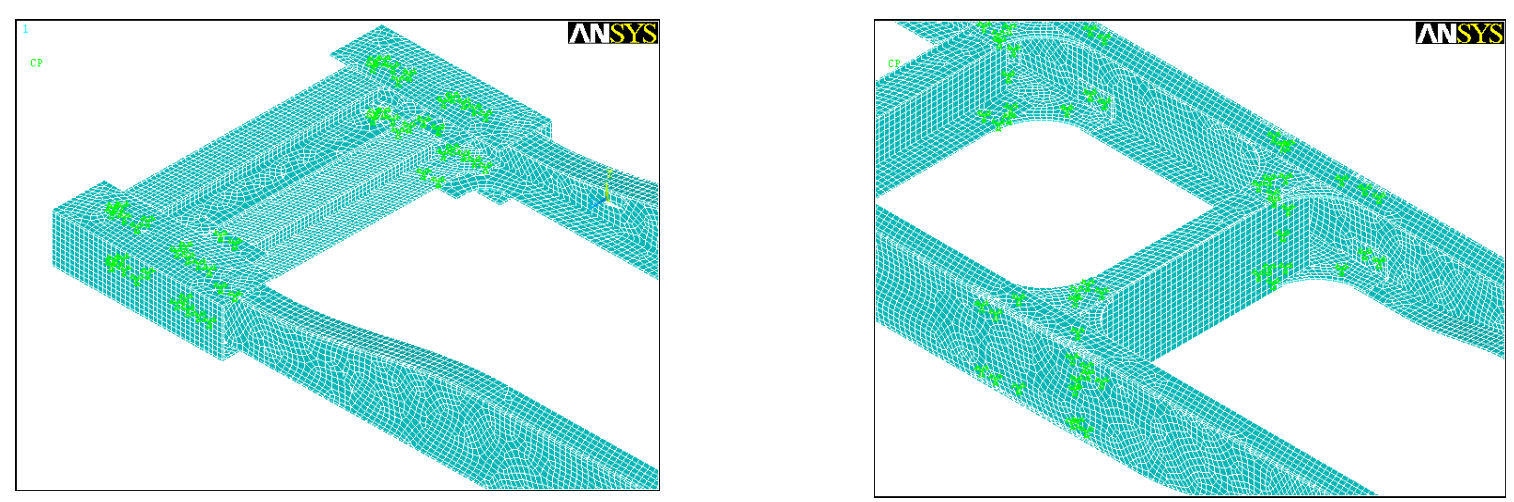

Figure(4) meshed chassis

The boundary conditions are different for each analysis. In normal mode analysis, free-free boundary condition will be applied to the truck chassis model, with no constraint applied to the chassis model[2]. A free-free boundary condition has been chosen as it is much simpler to test experimentally in this condition, if required.

\section{Modal analysis and results:}


We have performed modal analysis after creating the chassis finite element model and meshing, in free-free state and with no constraints. The results have been calculated for the first 30 frequency modes and show that road simulations are the most important problematic for truck chassis.

In this analysis we have made use of subspace method in ansys. Since chassis has no constraints, the first 6 frequency modes are vanish. 3 modes are related to the chassis displacement in $x, y$ and $z$ directions and 3 modes are related to chassis rotation about $x, y$ and $z$ axes. In figure (5) related natural frequencies and mode shapes for chassis with maximum displacement in y direction in each mode, have been shown.

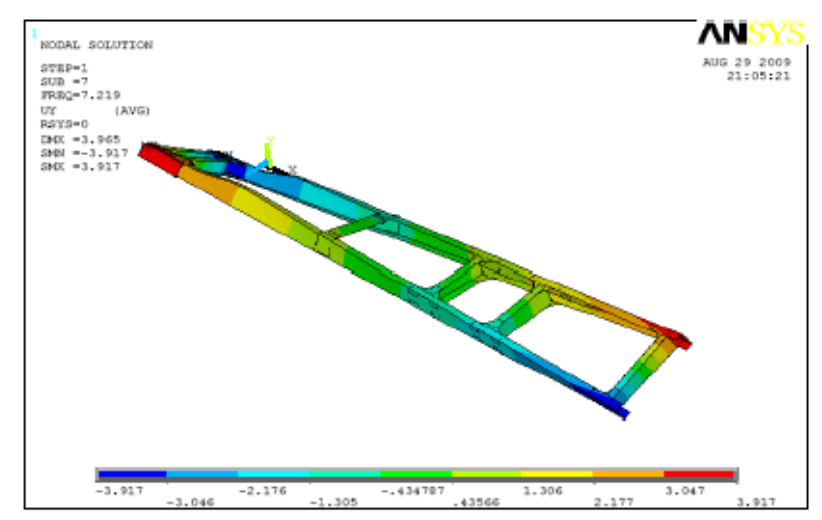

Mode 1:7.219 Hz

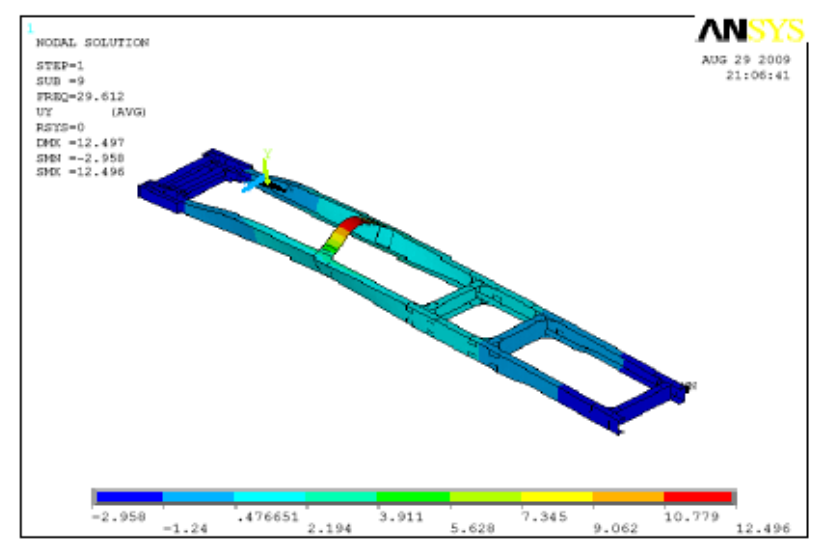

Mode 3:29.612 Hz

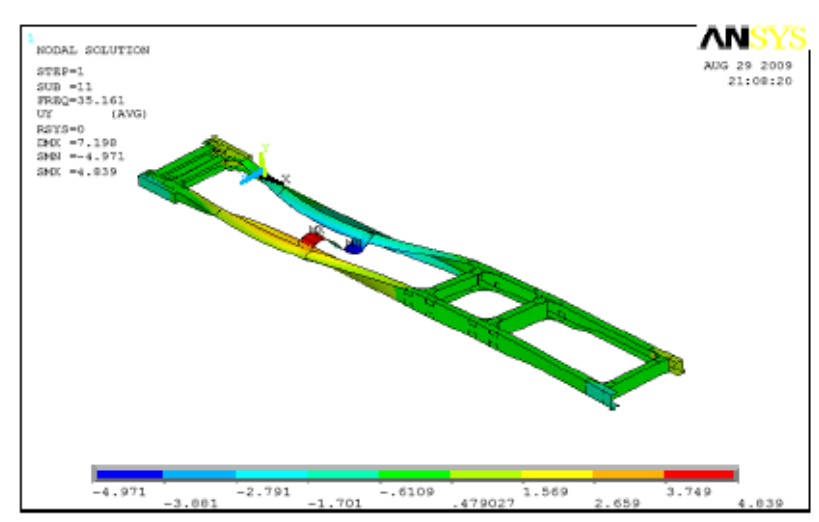

Mode 5:35.161 Hz

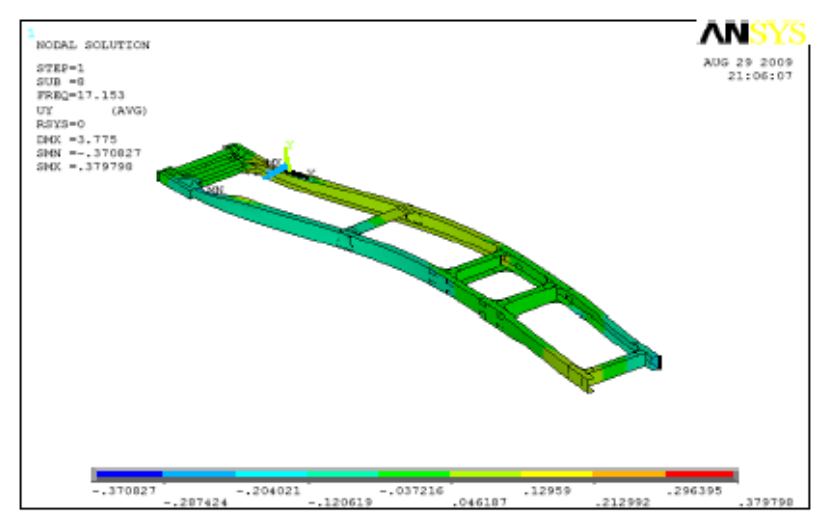

Mode $2: 17.153 \mathrm{~Hz}$

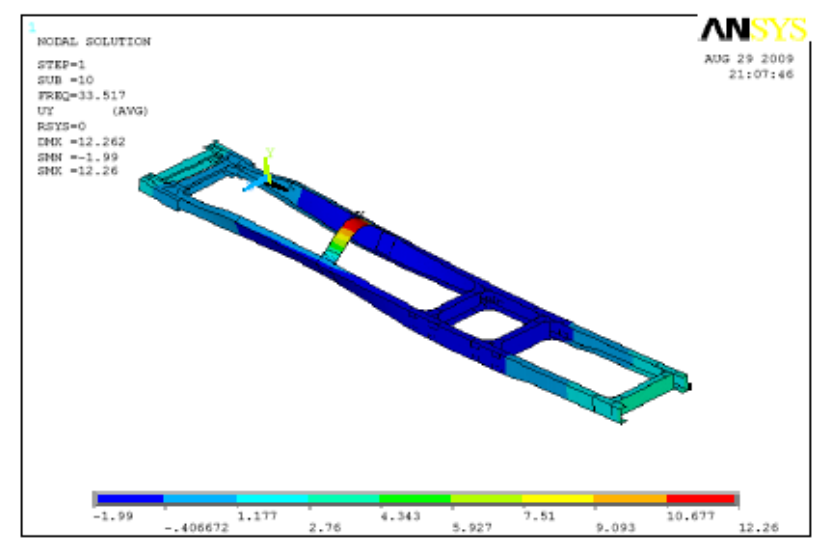

Mode $4: 33.517 \mathrm{~Hz}$

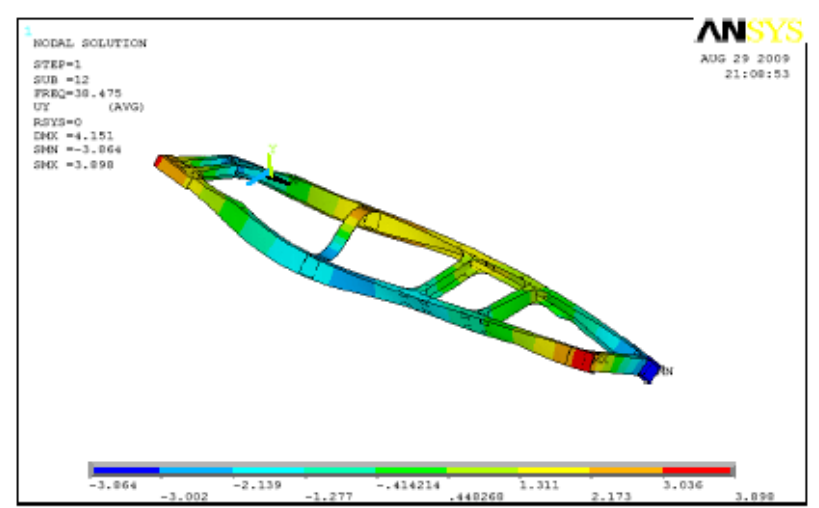

Mode 6:38.475 Hz

Figure(5) Natural frequencies of truck chassis 
Found natural frequencies from modal analysis of truck chassis, are used for determining the suitable situations for truck parts in working conditions.

Figure (5) shows that twisting mode with the frequency of $7.219 \mathrm{~Hz}$ is the prevailing mode. Second mode with $17.153 \mathrm{~Hz}$ frequency is the bending mode. Results of first 30 analysed modes for chassis are shown in table (2).

Table(2)

\begin{tabular}{|c|c|}
\hline Mode number & Natural frequency \\
\hline 1 & 0 \\
\hline 2 & 0 \\
\hline 3 & 0 \\
\hline 4 & 0 \\
\hline 5 & 0 \\
\hline 6 & 0 \\
\hline 7 & 7.2195 \\
\hline 8 & 17.153 \\
\hline 9 & 29.612 \\
\hline 10 & 33.517 \\
\hline 11 & 35.161 \\
\hline 12 & 38.475 \\
\hline 13 & 42.347 \\
\hline 14 & 46.692 \\
\hline 15 & 48.857 \\
\hline 16 & 67.016 \\
\hline 17 & 77.469 \\
\hline 18 & 82.553 \\
\hline 19 & 88.042 \\
\hline 20 & 93.700 \\
\hline 21 & 96.135 \\
\hline 22 & 100.43 \\
\hline 23 & 104.93 \\
\hline 24 & 106.79 \\
\hline 25 & 115.14 \\
\hline 26 & 117.26 \\
\hline 27 & 127.19 \\
\hline 28 & 127.93 \\
\hline 29 & 133.08 \\
\hline 30 & 154.39 \\
\hline
\end{tabular}

In general the natural frequency can be calculated using the equation (1);

$$
\omega_{n}=\sqrt{\frac{K}{m}}
$$

where $\mathrm{K}$ and $\mathrm{m}$ stand for stiffness and mass respectively. 
Diesel engine is known to have the operating speed varying from 8 to 33 revolutions per second (rps) [8]. In low speed idling condition, the speed range is about 8 to $10 \mathrm{rps}$. This translates into excitation frequencies varying from 24 to $30 \mathrm{~Hz}$ [2]. The main excitations are at low speeds, when the truck is in the first gear. At higher gear or speed, the excitations to the chassis are much less. The equipment installed on the chassis of municipal-service truck increase the chassis mass which leads to the decrease of natural frequencies. Regarding the previous discussions about the diesel engine speed, we can say that natural frequencies are in critical range. Hence with decreasing the chassis length which increases the chassis stiffness, we increase the natural frequencies to place them in the appropriate range.

In addition, with changing the gasoline tank situation and performing similar changes we can prevent coinciding the simulation force frequencies and natural frequencies. Otherwise resonance phenomenon occurs and if these two frequencies coincide, this phenomenon destroys the chassis.

\section{Conclusion:}

In this article we studied the changes of chassis dynamic behavior caused by change in usage. First six frequency modes of the modified chassis that determine its dynamic behavior are less than $40 \mathrm{~Hz}$. Since chassis mass increases due to the installed equipment, the natural frequencies fall out of the natural range that can be compensated with increasing the chassis stiffness. Decreasing the chassis length, can increase the chassis stiffness. Using this method, we can prevent resonance phenomenon and unusual chassis vibration and place the natural frequencies in natural range.

\section{References:}

[1] Frank Fahi and John Walker, "Advanced Applications in Acoustics, Noise and Vibration"

[2] Teo Han Fui, Roslan Abd. Rahman, "Statics and Dynamics Structural Analysis of a 4.5 TON TRUCK CHASSIS" ,Faculty of Mechanical Engineering, Universiti Teknologi Malaysia.

[3] Singiresu S.Rao,"Mechanical Vibration", 4th Edition

[4] Jason C. Brown, A. John Robertson, Stan T. Serpento "Motor vehicle structures"

[5] Vasek, M., Stejskal, V., Sika, Z., Vacalin, O., and , kovanda, J. "Dynamic Model of Truck for Suspension Control”, Vehicle System Dynamic Supplement 28 , pp.496505,1998 .

[6] Yuan Zhang and Arthur Tang, "New Approach for Vehicle System NVH Analysis" SAE International , Paper Number 981668.

[7] Y.Q. Guo, W.Q. Chen_, Y. H. Pao "Dynamic analysis of space frames", The method of Reverberation-ray matrix and the orthogonality of normal modes Received 23 January 2008; received in revised form 25 March 2008; accepted 29 March 2008.

[8] Johansson, I., Edlund, S., 1993. Optimization of Vehicle Dynamics in Trucks by Use of Full Vehicle FE-Models, Göteborg, Sweden, Department of Vehicle Dynamics \& Chassis Technology, Volvo Truck Corporation. 